\title{
Respiratory health and endotoxin: associations and modification by CD14/-260
} genotype

\author{
I. Bakolis, G. Doekes, J. Heinrich, J.P. Zock, D. Heederik, M. Kogevinas, S. Guerra, \\ D. Norbäck, A. Ramasamy, A. Nevalainen, C. Svanes, C.M. Chen, G. Verlato, \\ M. Olivieri, F. Castro-Giner and D. Jarvis on behalf of the Indoor Group of the \\ ECRHS and the Work Package 10 group of HITEA
}

ABSTRACT: Exposure to endotoxin has been associated with increased respiratory symptoms and decrements in lung function in occupational settings but little is known about the health effects of domestic exposure in adults. Here, we describe the association of respiratory disease, immunoglobulin (Ig)E sensitisation, bronchial reactivity and lung function with mattress endotoxin levels in adults, and determine whether these associations are modified by polymorphisms in CD14.

Endotoxin levels in mattress dust from a population-based sample of 972 adults were measured. Associations were examined using generalised linear mixed models, adjusting for individual and household confounders. Effect modification of these associations by CD14/-260 (rs2569190) was assessed.

Mattress endotoxin levels varied from 0.1 to $402.6 \mathrm{EU} \cdot \mathrm{mg}^{-1}$. Although there was no overall association of lung function with endotoxin exposure, there was evidence that the association of forced expiratory volume in $1 \mathrm{~s}$ and forced vital capacity with endotoxin was modified by CD14/-260 genotype ( $p$-value for interaction 0.005 and $\mathbf{0 . 0 1 3}$, respectively). There was no evidence that symptoms, IgE sensitisation or bronchial reactivity were associated with mattress endotoxin levels.

In this large epidemiological study of adults, there was no evidence that mattress endotoxin level was associated with respiratory symptoms or IgE sensitisation but the association of lung function with endotoxin levels may be modified by CD14 genotype.

KEYWORDS: Adults, CD14/-260 genotype, endotoxin, lung function, respiratory symptoms

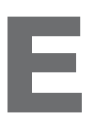
ndotoxin is a lipopolysaccharide molecule derived from the cell membrane of many Gram-negative bacteria, and is present in indoor [1], occupational [2] and outdoor environments [3]. There is substantial literature suggesting endotoxin exposure is associated with increased respiratory symptoms and decrements in lung function, particularly in environments with very high endotoxin exposure (e.g. pig farming and food processing) [2]. In the home environment, endotoxin exposure is much lower, but there have been reports that even at these levels, exposure is associated with an increased prevalence of wheeze in the first year of life [4], increased prevalence of sensitisation in 2-yr-olds [5], increased peak flow variability and asthma exacerbations in children [6], and increased prevalence of asthma [1] and asthma severity [7] in adults. In contrast, other studies suggest that residential exposure may lead to lower levels of allergic disease [8] and lower levels of immunoglobulin (Ig)E sensitisation in children [9] and a lower prevalence of severe $\operatorname{IgE}$ sensitisation in adults [10].

There is some evidence that polymorphisms in the CD14 gene are associated with atopic asthma [11], but more importantly, there is emerging evidence that these polymorphisms modify the effect of endotoxin on atopy and atopic disease. This may, to some extent, explain some of the reported inconsistencies in the association of endotoxin with disease. A recent review [12] identified four studies (three in children and one in families including adults) that supported a protective effect of carriage of the $C$ allele of the CD14/-260 genotype for atopy on exposure to endotoxin in the home environment.

We do not know of any reported population-based studies in adults that examined the association of
AFFILIATIONS

For a full list of the authors'

affiliations see the

Acknowledgements section.

\section{CORRESPONDENCE}

I. Bakolis

Respiratory Epidemiology and Public Health Group

National Heart and Lung Institute Imperial College

Emmanuel Kaye Building

Manresa Road

London SW3 6LR

UK

E-mail: i.bakolis@imperial.ac.uk

Received:

Oct 202010

Accepted after revision: July 242011

First published online:

Sept 012011 
respiratory outcomes with measured domestic endotoxin and possible effect modification by CD14. This report uses information collected as part of the European Community Respiratory Health Survey (ECRHS) and HITEA (Health Effects of Indoor Pollutants: Integrating Microbial, Toxicological and Epidemiological Approaches) to explore these associations.

\section{METHODS}

\section{Sample}

The methodology of the ECRHS II has been described previously [13]. Briefly, 29 centres performed a follow-up investigation of asthma, allergy, and their known or suspected risk factors (ECRHS II) in a random population sample of adults aged 2044 yrs at the baseline survey (ECRHS I, 1992-1994). In 2000-2002, participants were invited to a testing centre for interview, venesection for assessment of IgE sensitisation and lung function testing (forced expiratory volume in $1 \mathrm{~s}$ (FEV1), forced vital capacity (FVC) and bronchial reactivity to methacholine). Whole blood samples were taken for DNA extraction (except for centres in Italy and Iceland) at Helmholtz-Centrum (Munich, Germany).

In 22 centres in 10 countries, the homes of a sample of participants were visited to assess home exposures and to obtain a mattress dust sample. The objective was to assess 200 homes per centre, with home visits occurring as soon as possible after clinical assessment. Priority was given to participants who had not moved home between 1992-1994 and 2000-2002, and who, in 1992-1994, provided a blood sample for serum specific IgE testing.

Our study included 7,122 randomly selected individuals living in centres that took part in the indoor assessment (Italy: two centres; Belgium: two centres; Germany: two centres; Spain: five centres; France: two centres; UK: two centres; Sweden: three centres; Iceland: one centre; Switzerland: one centre; and Estonia: one centre). Of these, 3,043 had their mattress sampled, and 2,889 had sufficient dust for analysis for house dust mite and cat allergens. Only 2,124 had dust left after these tests and of these, 974 were randomly selected for endotoxin measures. Two participants were excluded (one for missing data and another because they were later identified as not randomly selected).

\section{Dust sampling}

Homes visits occurred from July 2000 to November 2002 in random order covering all seasons (median time between clinic visit and home visit 158 days, interquartile range 46-263 days). Fieldworkers were trained using a short video. The participant's bed was stripped of bedding, but mattress covers or protectors that had been in place for $\geqslant 3$ months were left. A template of $80 \times 125 \mathrm{~cm}$ was placed on the area where the participant usually slept. An ALK dust collection filter (ALK-Abello, Hørsholm, Denmark) was attached to an Electrolux Mondo vacuum cleaner (1,300 W; Electrolux, Stockholm, Sweden) and the area within the template $\left(1 \mathrm{~m}^{2}\right)$ was vacuumed for $2 \mathrm{~min}$. Within 3 days, samples were frozen for $24 \mathrm{~h}$ (to kill mites) and then stored at room temperature until transported with silica gel desiccant to a central laboratory. Samples were sieved to obtain fine dust for extraction and frozen at $-20^{\circ} \mathrm{C}$. The total dust weight was not recorded.

\section{Endotoxin measurement}

A random subsample of dust samples were thawed in 2008, split into approximately equal and homogeneous fractions of about 50-70 $\mathrm{mg}$, and transferred to pre-weighed 10-mL polystyrene vials with screw caps (Sterilin, Newport, UK). Samples were sent within days to Utrecht University (Utrecht, the Netherlands) and extracted in the same vials using a three-step procedure [14]. Endotoxin analysis was performed using the Limulus amoebocyte lysate assay (Lonza, Verviers, Belgium) with Escherichia coli endotoxin as the standard [15]. Results were expressed as endotoxin units (EU) per $\mathrm{mL}$ extract, and converted to an endotoxin concentration in $\mathrm{EU} \cdot \mathrm{mg}^{-1}$ sieved dust by multiplication by the extraction volume $(2.5 \mathrm{~mL})$ and division by the vial dust weight (in $\mathrm{mg}$ ).

\section{Genotyping}

In 2006, stored DNA was tested for single-nucleotide polymorphisms (SNPs) within the CD14, TLR2 and TLR4 genes using the SNPlex ${ }^{\mathrm{TM}}$ platform (Applied Biosystems, Foster City, CA, USA) according to manufacturer instructions, and analysed on an Applied Biosystems 3730/3730xl DNA Analyser. Allele calling was performed by clustering analysis using Genemapper version 4.0 (Applied Biosystems). The genotype call rate was $>98 \%$. Genotyping quality was controlled by inclusion of internal positive and negative controls provided by the manufacturer in the reaction plates, and incorporation of six duplicate samples of two HapMap reference trios in the genotyping process. Both genotype concordance and correct Mendelian inheritance were verified.

\section{Asthma score}

A continuous measure of asthma symptoms ranging from 0 to 5 was used [16]. It is the sum of positive responses to questions regarding the following symptoms in the previous 12 months: wheeze with breathlessness, chest tightness, attack of shortness of breath (SOB) at rest, $\mathrm{SOB}$ after exercise and being woken by SOB.

\section{Lung function}

Each participant was given up to nine attempts to provide two technically satisfactory forced expiratory manoeuvres. The highest recorded FEV1 and FVC were used to derive age-, sexand height-standardised residuals based on the prediction equations of QUANJER et al. [17] for FEV1, FVC and FVC/ FEV1.

\section{Other respiratory outcomes}

IgE sensitisation was defined as presence of allergen-specific IgE $>0.35 \mathrm{kU} \cdot \mathrm{L}^{-1}$ (Pharmacia, Uppsala, Sweden) in 2000-2002. Atopy was defined as any positive response to any of the three allergens tested (grass pollen, house dust mite and/or cat).

\section{Bronchial challenge}

Bronchial hyperresponsiveness (BHR) to methacholine was measured using a dosing schedule that delivered methacholine to a maximum dose of $1 \mathrm{mg}$. Methacholine was delivered via a Mefar dosimeter (Mefar, Bovezzo, Italy), FEV1 was recorded $2 \mathrm{~min}$ after each inhalation and the test stopped when either a $20 \%$ fall in FEV1 had been achieved or the final dose had been given [18-20]. The term "slope" is used for transformed logarithmic slope as used in the ECRHS [18-20] with a low slope indicative of high BHR, with values ranging from 1 to 20 [21]. 


\section{Statistical analysis}

The association of asthma score with the level of exposure to mattress endotoxin (log-transformed to account for skewness) controlling for personal factors (age, sex and smoking status in pack-yrs) and for household variables (keeping a cat/dog, age of mattress, presence of mould in the bedroom, presence of dampness in the bedroom, household density and age of home) was assessed using a random-intercept, negative binomial model set to take account of clustering of individuals within countries.

The association of $\mathrm{IgE}$ sensitisation to any of grass pollen, house dust mite or cat allergen was assessed using generalised linear mixed models controlling for the same personal and household factors. Similar analyses were conducted to examine associations with: geometric mean (GM) total IgE; BHR; age-, sex- and height-standardised residuals of FEV1; age-, sexand height-standardised residuals of FVC; and age-, sex- and height-standardised residuals of FEV1/FVC.

Effect modification of the association of respiratory outcomes with endotoxin level by CD14/-260 genotype was tested by the inclusion of an interaction term assuming an additive genetic model.

Linearity of observed associations was tested with the use of generalised additive mixed models (GAMMs).

Statistical analyses were conducted using STATA 10 (Stata Corporation, College Station, TX, USA) with GAMMs also performed in R (www.r-project.org).

In all centres, permission to conduct this study was obtained from appropriate local ethics committees.

\section{RESULTS}

\section{Participants}

This analysis included 972 adults living in 21 centres in 10 countries. Compared with participants in the ECRHS II, but who did not have endotoxin measured $(n=6,150$; see Methods section), our sample had a similar proportion of males $(50.6 \%$ versus $50.5 \% ; \mathrm{p}=0.400$ ) and was older (mean age 44.4 versus $42.5 \mathrm{yrs} ; \mathrm{p}<0.001)$. There was a similar proportion of smokers $(29.1 \%$ versus $29.6 \% ; \mathrm{p}=0.440)$ and of those reporting wheeze in the last year $(21.7 \%$ versus $19.9 \%$; $=0.107)$. Asthma score was similar (Chi-squared test $p=0.297$ ). Genotyping was not performed in Italy or Iceland; in the remaining centres, $63.7 \%$ of participants agreed to genotyping.

Endotoxin levels varied from 0.1 to $402.6 \mathrm{EU} \cdot \mathrm{mg}^{-1}$ (GM 2.4 $\mathrm{EU} \cdot \mathrm{mg}^{-1}, 95 \%$ CI $2.2-2.6 \mathrm{EU} \cdot \mathrm{mg}^{-1}$; 5 th percentile $0.3 \mathrm{EU} \cdot \mathrm{mg}^{-1}$, 95th percentile $17.8 \mathrm{EU} \cdot \mathrm{mg}^{-1}$ ).

Table 1 presents demographic data of those included in this analysis and descriptive statistics for the outcomes considered.

\section{Asthma score}

Overall, there was no association of asthma score with mattress endotoxin level (table 2), even when asthma was considered separately in atopic and nonatopic participants (all $\mathrm{p}>0.1$; data not shown). There was no evidence of a non-linear association (using a smoothing spline in GAMM, $\mathrm{p}=0.207$ ). There was no evidence that the association was present in some countries and not in others (test of between country heterogeneity, $p>0.1$ ), although the low number of subjects in some countries limited the extent to which this could be explored. Results were similar whether asthma score was analysed in its recommended form (a continuous variable) and as a binary variable (positive answer to any of the five questions compared to negative answers to all) (table 2).

The association of asthma score with endotoxin level was not modified by CD14 genotype (interaction $\mathrm{p}>0.05$ ) using an additive genetic model. However, there were differences in the association between the genotypes, such that the adjusted ratio of mean asthma score per 10-fold change in endotoxin level was 1.86 (95\% CI 1.19-2.91) for the CT allele (table 2).

\begin{tabular}{|c|c|c|}
\hline & $\begin{array}{c}\text { Total with } \\
\text { information } n\end{array}$ & Proportion \\
\hline Age yrs & 972 & $44.4(38.0-53.6)$ \\
\hline Females & $481 / 972$ & 49.4 \\
\hline \multicolumn{3}{|l|}{ Asthma score } \\
\hline 0 & $673 / 972$ & 69.1 \\
\hline 1 & $172 / 972$ & 17.7 \\
\hline 2 & $75 / 972$ & 7.7 \\
\hline 3 & 23/972 & 2.3 \\
\hline 4 & $18 / 972$ & 1.8 \\
\hline 5 & $12 / 972$ & 1.2 \\
\hline \multicolumn{3}{|l|}{ Smokers } \\
\hline Never & 408/972 & 41.9 \\
\hline Ever & 280/972 & 28.8 \\
\hline Current & $283 / 972$ & 29.1 \\
\hline Hay fever/nasal allergies & $251 / 972$ & 25.8 \\
\hline IgE to HDM & $140 / 972$ & 14.4 \\
\hline IgE to grass pollen & $117 / 972$ & 12.0 \\
\hline $\lg E$ to cat & $66 / 972$ & 6.7 \\
\hline IgE to HDM, grass pollen or cat & $235 / 972$ & 24.1 \\
\hline Geometric mean IgE kU $\cdot \mathrm{L}^{-1}$ & 874 & 39.8 \\
\hline Proportion with FEV $1<$ LLN $^{\#}$ & $54 / 909$ & 6.9 \\
\hline Proportion with FVC $<$ LLN $^{\#}$ & $46 / 909$ & 5.1 \\
\hline Cat or dog in house & $316 / 972$ & 32.5 \\
\hline Mould in bedroom & $63 / 972$ & 6.4 \\
\hline Damp in bedroom & $43 / 972$ & 4.4 \\
\hline House built before 1970 & $467 / 972$ & 48.0 \\
\hline Mattress $<1 \mathrm{yr}$ old & $53 / 972$ & 5.5 \\
\hline Household density & 961 & $0.75(0.3-1.3)$ \\
\hline \multicolumn{3}{|l|}{ CD14/-260 rs2569190" } \\
\hline $\mathrm{CC}$ & $126 / 561$ & 22.4 \\
\hline СТ & $282 / 561$ & 50.2 \\
\hline$\pi$ & $153 / 561$ & 27.3 \\
\hline
\end{tabular}

Data are presented as median (interquartile range) or \%, unless otherwise stated. Ig: immunoglobulin; HDM: house dust mite; FEV1: forced expiratory volume in $1 \mathrm{~s}$; LLN: lower limit of normal; FVC: forced vital capacity. "*: LLN from [22]; ": in addition, two tagging single-nucleotide polymorphisms (tagSNPs) in TLR2 (rs1816702 and rs1898830) were found in 562 and 560 individuals, respectively, and five tagSNPs in TLR4 (rs1554973, rs1927914, rs2737191, rs10759930 and rs11536889) in 567, 564, 567, 566 and 516 individuals, respectively. 


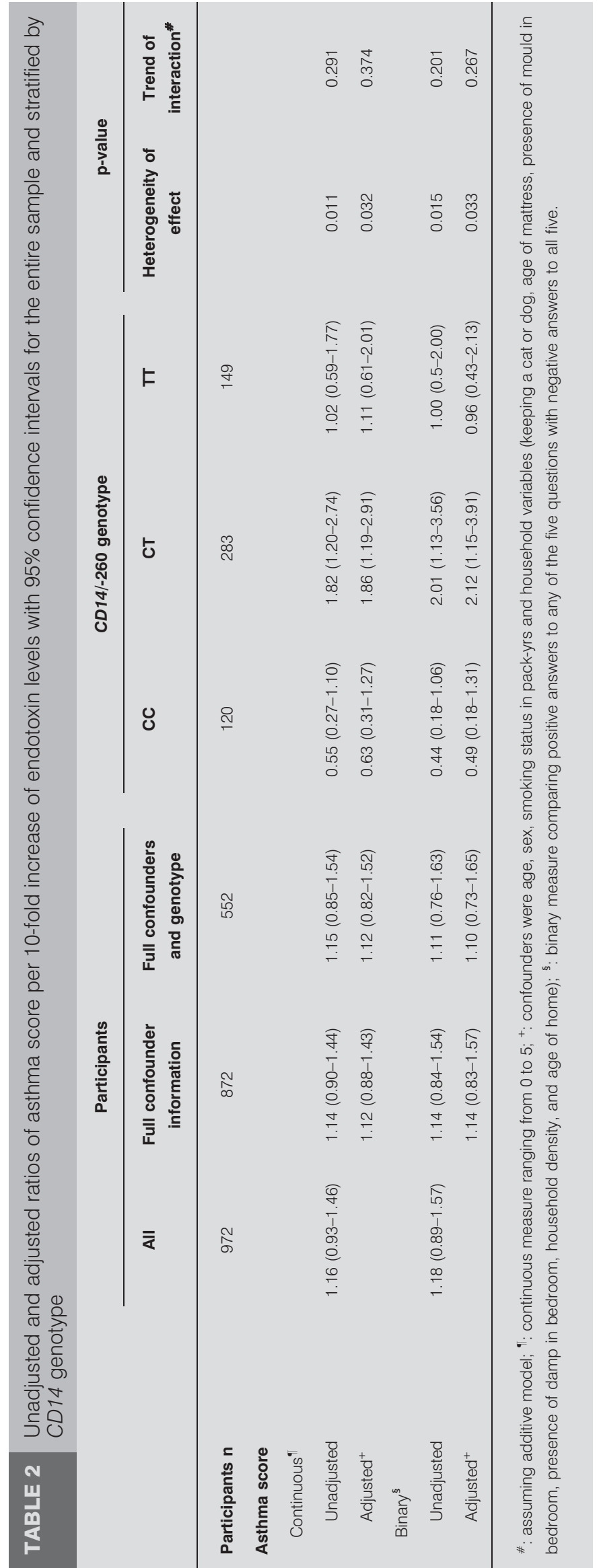

\section{IgE sensitisation and BHR}

There was no significant association of IgE sensitisation to house dust mite, grass or cat allergen with endotoxin level or any association of total $\operatorname{IgE}$ and BHR slope with endotoxin level (table 3).There was no evidence that these associations were modified by $C D 14 /-260$ genotype (data not shown).

\section{Lung function}

Overall, there was no evidence of an association of either FEV1, FVC or FEV1/FVC with endotoxin levels (table 4), even if analyses were stratified by atopy (data not shown).

There was, however, strong evidence that the association of FEV1 and FVC with endotoxin levels was modified by CD14 genotype (test for heterogeneity of effect $p=0.008$ and $p=0.029$, respectively). For a 10 -fold increase in mattress endotoxin level, those with the CC genotype showed an improvement in FEV1 residuals of 0.62 standard deviations (95\% CI $0.21-1.04$ ) greater than the predicted value. In those carrying the TT genotype, a similar increase in exposure was associated with a nonsignificant decrement in lung function $(-0.22$; $95 \%$ CI -0.59 0.13). The CT genotype showed an intermediate association (trend across the three genotypes $\mathrm{p}=0.005$ ).

Figure 1 shows the smoothed association using GAMM, confirming linearity in each of the three genotypes (using a smoothing spline, $\mathrm{p}>0.05)$.

Table 5 presents some results stratified by atopy. Table 5 should be interpreted cautiously as the effect estimates in atopics and nonatopics by each genotype are based on small numbers (as shown by the wide confidence intervals). In both atopics and nonatopics, the relationship of lung function with endotoxin was different in the three CD14 genotypes for FEV1 $(p=0.028$ and $p=0.001$, respectively) (table 5). These different effects by genotype were seen for FVC in nonatopics $(p=0.008)$ and for FEV1/FVC ratio $(p=0.018)$ in atopics. However, statistical testing showed that any apparent differences between atopics and nonatopics could have arisen by chance, and that the effect of CD14 genotype on lung function responses to endotoxin was the same in atopics and nonatopics.

There was no evidence of between-country heterogeneity in this gene-environment interaction, although the number of individuals with complete data in each country was relatively small. In figure 2, we show the change in FEV1 standardised residuals per 10-fold increase in mattress endotoxin levels by northern (Sweden, Estonia and Iceland), middle (UK, Belgium, France, Germany and Switzerland) and southern (Spain and Italy) Europe. Variation in the association of FEV1 with endotoxin by CD14 genotype was most clearly seen in the northern European centres, but in each of the three regions, data were consistent with the overall findings.

\section{Other genotypes}

$T L R$ genes have also been proposed to modify the response to the endotoxin-rich farming environment [23]. As participants had also been genotyped for SNPs within TLR2 (rs1816702 and rs1898830) and TLR4 (rs10759930, rs1927914, rs1554973, rs2737191 and rs11536889) associations were tested in a similar manner to CD14. In this post hoc analysis, there was no evidence that any of the SNPs modified the association of 


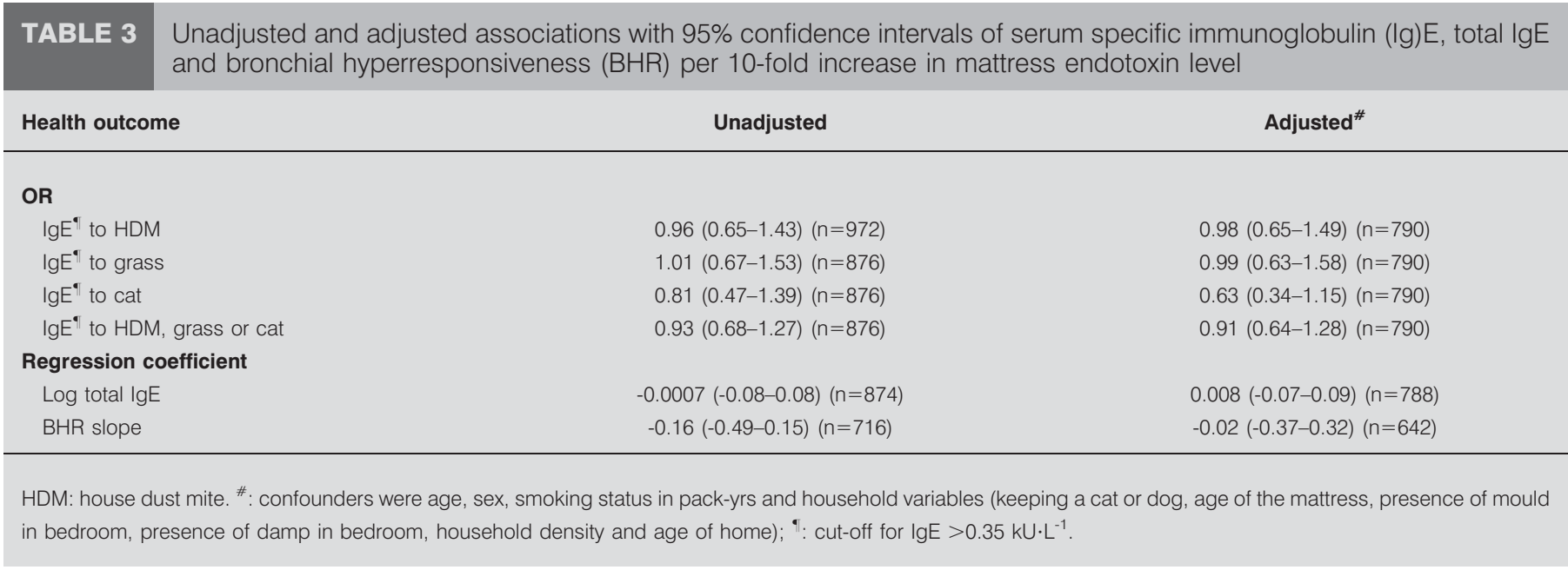

health outcomes with exposure to endotoxin (all tests for interaction, $\mathrm{p}>0.06)$.

\section{DISCUSSION}

In this multinational study of middle-aged adults, we found no overall association of lung function with mattress endotoxin levels, although we did find evidence that this association may be modified by CD14 genotype. There was no evidence of an association of respiratory symptoms or sensitisation to environmental allergen with mattress endotoxin levels.

There are a limited number of studies in adults in which the association of allergic and respiratory disease with directly measured domestic endotoxin has been examined. The largest of these reported an association of current wheeze and asthma medication use with endotoxin levels in bedding in the USA [1]. The methods used to assess endotoxin levels were similar to ours but the range of measured endotoxin levels was higher than we observed in our study (GM endotoxin level in bedding 18.7 EU. $\mathrm{mg}^{-1}$, 5th percentile $2.0 \mathrm{EU} \cdot \mathrm{mg}^{-1}$ and 95th percentile $\left.142 \mathrm{EU} \cdot \mathrm{mg}^{-1}\right)$. Their analysis suggested that associations of symptoms with endotoxin level were present in adults, but not in children. In another study in Germany, the homes of 350 adults taking part in the first phase of the ECRHS I had living room dust samples taken for endotoxin assay in 1995-1996 (GM 4.4 $\mathrm{EU} \cdot \mathrm{mg}^{-1}$, range $0.2-1,661 \mathrm{EU} \cdot \mathrm{mg}^{-1}$ ) [24]. There was some evidence that higher levels of endotoxin were associated with a lower prevalence of $\operatorname{IgE}$ sensitisation, which was most evident when $\operatorname{IgE}$ sensitisation was defined by a higher cut-off than we have used $\left(>3.5\right.$ rather than $\left.0.35 \mathrm{kU} \cdot \mathrm{L}^{-1}\right)$ and was particularly strong for grass pollen. Even when we looked in our data for a relationship with endotoxin with this higher level of sensitisation to grass pollen, we saw no effect (adjusted OR 0.90, 95\% CI 0.48-1.69). A family based study in Barbados, which included adults, showed no overall association of living room endotoxin levels with asthma, asthma severity or total IgE [25].

The aforementioned studies sampled endotoxin from a variety of indoor sites. Living room floor dust levels tend to be higher than mattress levels but the two have been shown to be weakly or moderately correlated in several studies conducted in Europe and the USA [4, 14, 26-28]. THORNE et al. [1], in the USA, measured endotoxin in the living room (floor and sofa) and in the bedroom (floor and bedding). Symptoms suggestive of asthma were associated with endotoxin in all locations, but this was most strongly and significantly seen for the bedroom measurements. This might reflect that exposure in the bedroom is longer $\left(\sim 8 \mathrm{~h} \cdot \mathrm{day}^{-1}\right)$ and, for mattress levels, is more intense (as the endotoxin is closer to the breathing zone). We have only measured mattress dust levels, but further studies could include other indoor sites, particularly as the relative contribution of each source of endotoxin may differ between locations [29].

None of the studies that have examined health effects of domestic exposure in adults have examined lung function. We did not see an overall association of lung function with mattress endotoxin, even though there is a substantial body of literature suggesting that low lung function is associated with workplace endotoxin exposure [2] and that there is a doserelated inflammatory response in the lung to inhaled endotoxin [30]. It is highly likely that exposures in workplace settings are higher than those in the domestic environment, but direct comparison of our results with these other studies is hindered by differences in sampling methods.

We did see strong evidence that the association of endotoxin with lung function may be modified by CD14/-260 genotype. This gene-environment interaction did not exactly follow the pattern suggested by previous studies, which have examined related respiratory outcomes. In the nonoccupational environment, increasing endotoxin exposure has been associated with better health outcomes in those carrying the C allele of CD14/ -159 (more recently referred to as $C D 14 /-260$ ) when compared with those with the $\mathrm{T}$ allele (e.g. less $\mathrm{IgE}$ sensitisation in UK children [12], lower total $\mathrm{IgE}$ in rural and farm children in Germany [31], less asthma in families in Barbados [25], and lower total IgE in pregnant mothers [32] and their offspring [33] in the USA). This has been interpreted as evidence that the presence of the $C$ allele confers suppression of atopic T-helper cell type-2 responses in the presence of endotoxin. We anticipated that carriage of the $\mathrm{C}$ allele would protect against endotoxin-related decrements in lung function, a protection that would not be seen in those with the $\mathrm{T}$ allele. However, we observed an improvement in lung function with endotoxin exposure in those carrying the $C$ allele, with little or no change 


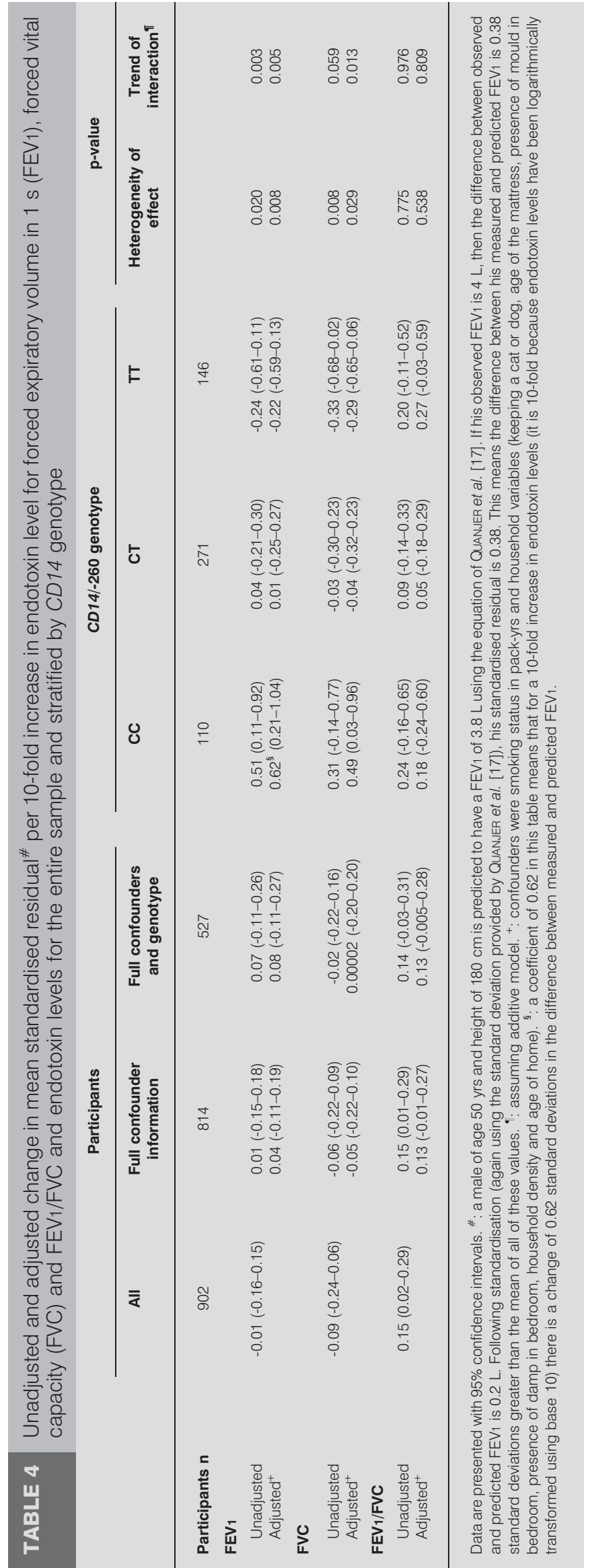

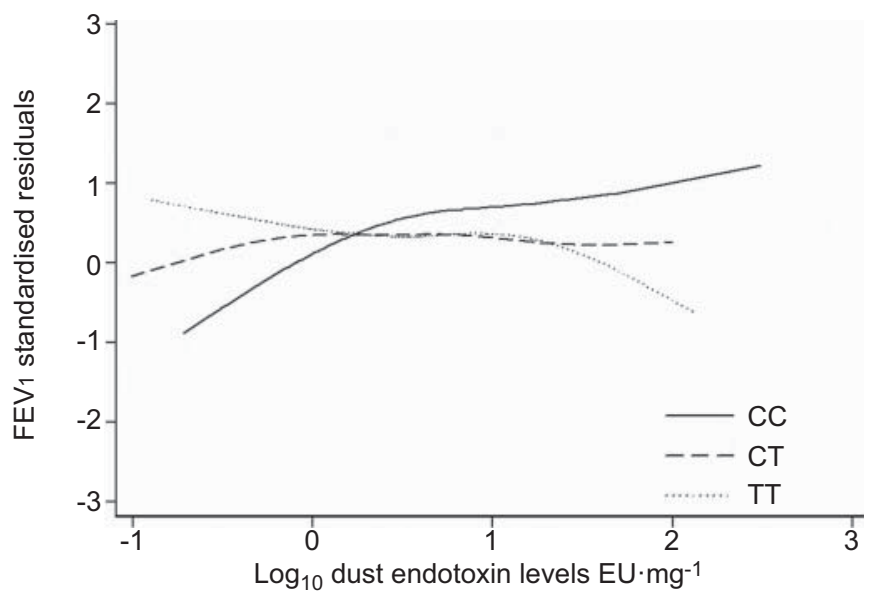

FIGURE 1. Generalised additive mixed model (GAMM) plot, after the fitting of a GAMM adjusted for smoking status and household variables, of the relationship between log-transformed dust endotoxin levels and forced expiratory volume in $1 \mathrm{~s}$ (FEV1) standardised residuals by CD14 genotype. TT denotes individuals homozygous for the cytosine $(\mathrm{C})$ to thymine $(\mathrm{T})$ transition at position -260 of CD14, CT denotes individuals heterozygous for the transition and CC denotes individuals homozygous for cytosine at both alleles.

seen in those with the $\mathrm{T}$ allele. Our data support there being differential responses to endotoxin between the $C D 14$ genotypes and that the $\mathrm{C}$ allele is beneficial in the presence of high levels of endotoxin; although we find it difficult to understand why better lung function with increasing exposure is seen in this group, we make the following observations. First, in nonatopic subjects with the TT genotype, endotoxin was significantly associated with reduced lung function. The association was of borderline significance in nonatopics carrying the CC genotype. Secondly, the genotype effects predicted by the GAMM plot (fig. 1) among subjects heavily exposed to endotoxin were largely consistent with results from occupationally exposed

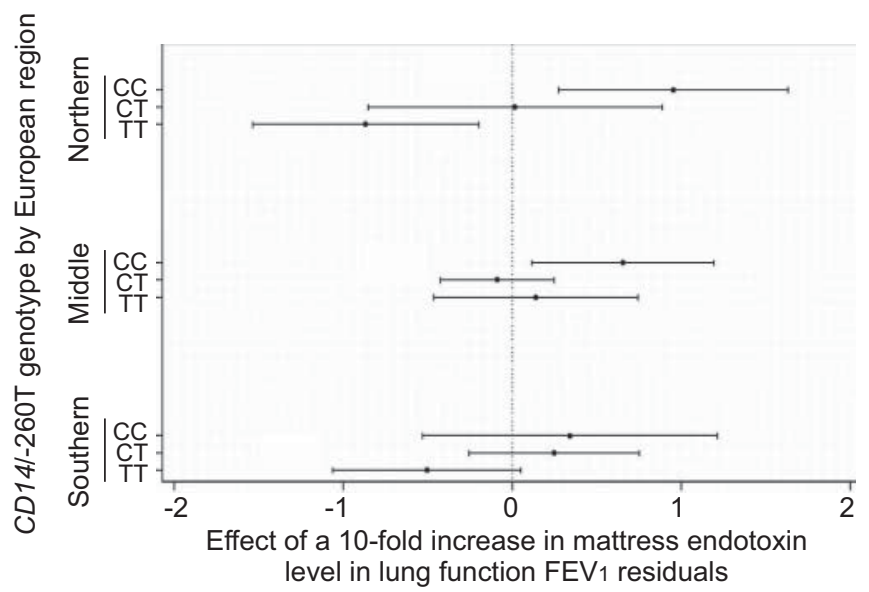

FIGURE 2. Estimated effect of a 10 -fold increase in mattress endotoxin level in lung function (forced expiratory volume in $1 \mathrm{~s}$ (FEV1) standardised residuals) across the three genotypes of CD14/-260 (rs2569190) for three European regions. Endotoxin levels by region were as follows. South: median 3.1 (5th to 95th percentile 0.5-17.2); middle: median 2.7 (5th to 95th percentile 0.5-19.7); north: median 1.5 (5th to 95th percentile 0.3-18.2). Whiskers represent 95\% confidence intervals. 


\begin{tabular}{|c|c|c|c|c|c|c|}
\hline \multirow[t]{2}{*}{ TABLE 5} & \multicolumn{6}{|c|}{$\begin{array}{l}\text { Adjusted change in mean standardised residual }{ }^{\#} \text { per 10-fold increase in endotoxin level for forced expiratory volume in } \\
1 \text { s (FEV } 1 \text { ), forced vital capacity (FVC) and FEV1/FVC and endotoxin levels for atopics and nonatopics and stratified by } \\
\text { CD14 genotype }\end{array}$} \\
\hline & $\mathrm{CC}$ & Ст & TT & $\begin{array}{c}\text { Heterogeneity } \\
\text { of effect }\end{array}$ & $\begin{array}{c}\text { Trend of } \\
\text { interaction }\end{array}$ & $\begin{array}{l}\text { Test of difference in } \\
\text { effect of } C D 14 \text { on lung } \\
\text { function response to } \\
\text { endotoxin }\end{array}$ \\
\hline \multicolumn{7}{|c|}{ FEV $_{1}$, adjusted ${ }^{\S}$} \\
\hline Nonatopics & $0.46(-0.03-0.96)(n=84)$ & $0.08(-0.21-0.38)(n=191)$ & $-0.39(-0.78--0.01)(n=104)$ & 0.028 & 0.004 & 0.091 \\
\hline Atopics & $1.11(0.67-1.55)(n=26)$ & $-0.13(-0.71-0.43)(n=79)$ & $0.16(-0.67-1.00)(n=41)$ & 0.001 & 0.273 & \\
\hline \multicolumn{7}{|c|}{ FVC, adjusted ${ }^{\mathfrak{s}}$} \\
\hline Atopics & $1.44(0.60-2.27)(n=26)$ & $0.02(-0.50-0.55) \quad(n=80)$ & $0.31(-0.25-0.88)(n=41)$ & 0.018 & 0.221 & \\
\hline
\end{tabular}

Data are presented with $95 \%$ confidence intervals. ${ }^{*}$ : a male of age $50 \mathrm{yrs}$ and height $180 \mathrm{~cm}$ is predicted to have a FEV1 of 3.8 L using the equation of QUAN.JER et al. [17]. If his observed FEV1 is $4 \mathrm{~L}$, then the difference between observed and predicted FEV 1 is $0.2 \mathrm{~L}$. Following standardisation (again using the standard deviation provided by QUANJER et al. [17]), his standardised residual is 0.38 . This means the difference between his measured and predicted FEV 1 is 0.38 standard deviations greater than the mean of all of these values. ' : additive model. ${ }^{+}$: comparing atopics and nonatopics, p-value of hypothesis that a linear effect of a three-way interaction term (endotoxin $\times$ CD14/-260C to $T \times$ atopy) is equal to $0 .{ }^{\text {s. }}$ : confounders were age, sex, smoking status in pack-yrs and household variables (keeping a cat or dog, age of the mattress, presence of mould in bedroom, presence of damp in bedroom, household density and age of home).

cohorts [34]. Thirdly, this gene-environment interaction is worthy of further consideration in light of the strong evidence against the null hypothesis $(\mathrm{p}=0.003)$. Finally, our analysis clearly indicates that associations of lung function with endotoxin in heterozygotes are intermediate of those for the two homozygote states and that this pattern of association is consistent across different parts of Europe.

In those with the CC genotype, we also saw that endotoxin exposure was nonsignificantly $(\mathrm{p}>0.05)$ protective for asthma score, a finding consistent with that for lung function. There was also some evidence that the association of asthma score with endotoxin was different in the CT genotype compared with the other two homozygous states. This might be interpreted as indicative of heterosis (the biological phenomenon in which an effect is most pronounced in the heterozygote), and a small study has suggested heterosis could exist with respect to CD14 genotype and interleukin-6 levels [35]. Replication in other large studies of adults is required, although, at present, few studies have collected necessary data on exposure, symptoms as defined and genotype.

The role of lipopolysaccharide and the bioactive moiety endotoxin have recently been extensively reviewed by SIMPSON and MARTINEZ [12], and they argue that discrepancies in the literature on the relation of endotoxin exposure to atopy may have arisen due to differential effects in those carrying different genotypes for CD14. Although we found no evidence of this for atopy or symptoms, we did observe this interaction for lung function. This did not appear to be mediated by downregulation of atopic responses, as we saw no evidence that endotoxin exposure was associated with less atopy. Our definition of atopy relied on sensitisation to the three major aeroallergens in Europe, which identify most individuals with IgE sensitisation to aeroallergens [36].

In conclusion, this multicentre European study has provided a valuable resource to examine the health effects of residential exposure to endotoxin in almost 1,000 adults with detailed information on respiratory disease and CD14/-260 genotype. We found little evidence that exposure to mattress endotoxin was associated with reported respiratory symptoms. There was evidence, however, that the association of lung function with mattress endotoxin level may be modified by the CD14/-260 genotype.

\section{SUPPORT STATEMENT}

The coordination of the ECRHS II was supported by the European Commission, as part of their Quality of Life programme, who also funded the indoor environmental assessment (grant code QLK4-CT1999-01237). This work was supported by the European Commission as part of HITEA (Health Effects of Indoor Pollutants: Integrating Microbial, Toxicological and Epidemiological Approaches) (grant agreement number 211488 under the Seventh Framework Programme, Topic ENV.2007.1.2.1.1: "Indoor air pollution in Europe: an emerging environmental health issue ${ }^{\prime \prime}$ ).

\section{STATEMENT OF INTEREST}

None declared.

\section{ACKNOWLEDGEMENTS}

The author's affiliations are: I. Bakolis, Respiratory Epidemiology and Public Health, National Heart and Lung Institute, Imperial College London, London, UK; G. Doekes, Institute for Risk Assessment Sciences, Division of Environmental Epidemiology, University of Utrecht, Utrecht, 
the Netherlands; J. Heinrich, Helmholtz Zentrum München, German Research Centre for Environmental Health, Institute of Epidemiology, Munich, Germany; J.P. Zock, Centre for Research in Environmental Epidemiology, Hospital del Mar Research Institute and CIBER Epidemiologia y Salud Pública, Barcelona, Spain; D. Heederik, Institute for Risk Assessment Sciences, Division of Environmental Epidemiology, University of Utrecht, Utrecht, the Netherlands; M. Kogevinas, Centre for Research in Environmental Epidemiology, Hospital del Mar Research Institute and CIBER Epidemiologia y Salud Pública, Barcelona, Spain, and National School of Public Health, Athens, Greece; S. Guerra, Centre for Research in Environmental Epidemiology, Hospital del Mar Research Institute and CIBER Epidemiologia y Salud Pública, Barcelona, Spain; D. Norbäck, Dept of Medical Science, Occupational and Environmental Medicine, Uppsala University, Uppsala, Sweden; A. Ramasamy, Respiratory Epidemiology and Public Health, National Heart and Lung Institute, Imperial College London, London, UK; A. Nevalainen, Dept of Environmental Health, National Institute for Health and Welfare, Kuopio, Finland; C. Svanes, Bergen Respiratory Research Group, Institute of Medicine, University of Bergen, Bergen, Norway; C.M. Chen, Helmholtz Zentrum München, German Research Centre for Environmental Health, Institute of Epidemiology, Munich, Germany; G. Verlato, Epidemiology and Medical Statistics, University of Verona, Verona, Italy; M. Olivieri, Dept of Medicine and Public Health, Unit of Occupational Medicine, University of Verona, Verona, Italy; F. CastroGiner, Centre for Research in Environmental Epidemiology, Hospital del Mar Research Institute and CIBER Epidemiologia y Salud Pública, Barcelona, Spain; and D. Jarvis, Respiratory Epidemiology and Public Health, National Heart and Lung Institute, Imperial College London, and MRC-HPA Centre for Environment and Health, London, UK.

\section{REFERENCES}

1 Thorne PS, Kulhankova K, Yin M, et al. Endotoxin exposure is a risk factor for asthma: the national survey of endotoxin in United States housing. Am J Respir Crit Care Med 2005; 172: 1371-1377.

2 Liebers V, Bruning T, Raulf-Heimsoth M. Occupational endotoxinexposure and possible health effects on humans. Am J Ind Med 2006; 49: 474-491.

3 Heinrich J, Pitz M, Bischof W, et al. Endotoxin in fine (PM2.5) and coarse (PM2.5-10) particle mass of ambient aerosols. A temporospatial analysis. Atmos Environ 2003; 37: 3659-3667.

4 Park JH, Gold DR, Spiegelman DL, et al. House dust endotoxin and wheeze in the first year of life. Am J Respir Crit Care Med 2001; 163: 322-328.

5 Bolte G, Bischof W, Borte M, et al. Early endotoxin exposure and atopy development in infants: results of a birth cohort study. Clin Exp Allergy 2003; 33: 770-776.

6 Rizzo MC, Naspitz CK, Fernandez-Caldas E, et al. Endotoxin exposure and symptoms in asthmatic children. Pediatr Allergy Immunol 1997; 8: 121-126.

7 Michel O, Kips J, Duchateau J, et al. Severity of asthma is related to endotoxin in house dust. Am J Respir Crit Care Med 1996; 154: 1641-1646.

8 Braun-Fahrlander C, Riedler J, Herz U, et al. Environmental exposure to endotoxin and its relation to asthma in school-age children. N Engl J Med 2002; 347: 869-877.

9 Gehring U, Bischof W, Fahlbusch B, et al. House dust endotoxin and allergic sensitization in children. Am J Respir Crit Care Med 2002; 166: 939-944.

10 Gehring U, Bischof W, Borte M, et al. Levels and predictors of endotoxin in mattress dust samples from East and West German homes. Indoor Air 2004; 14: 284-292.

11 Zhang Y, Tian C, Zhang J, et al. The $-159 \mathrm{C} / \mathrm{T}$ polymorphism in the $\mathrm{CD} 14$ gene and the risk of asthma: a meta-analysis. Immunogenetics 2011; 63: 23-32.
12 Simpson A, Martinez FD. The role of lipopolysaccharide in the development of atopy in humans. Clin Exp Allergy 2010; 40: 209-223.

13 European Community Respiratory Health Survey II Steering Committee. The European Community Respiratory Health Survey II. Eur Respir J 2002; 20: 1071-1079.

14 Schram D, Doekes G, Boeve M, et al. Bacterial and fungal components in house dust of farm children, Rudolf Steiner school children and reference children - the PARSIFAL Study. Allergy 2005; 60: 611-618.

15 Spaan S, Doekes G, Heederik D, et al. Effect of extraction and assay media on analysis of airborne endotoxin. Appl Environ Microbiol 2008; 74: 3804-3811.

16 Sunyer J, Pekkanen J, Garcia-Esteban R, et al. Asthma score: predictive ability and risk factors. Allergy 2007; 62: 142-148.

17 Quanjer PH, Tammeling GJ, Cotes JE, et al. [Lung volumes and forced ventilatory flows. Work Group on Standardization of Respiratory Function Tests. European Community for Coal and Steel. Official position of the European Respiratory Society]. Rev Mal Respir 1994; 11: Suppl. 3, 5-40.

18 Chinn S, Burney P, Sunyer J, et al. Sensitization to individual allergens and bronchial responsiveness in the ECRHS. European Community Respiratory Health Survey. Eur Respir J 1999; 14: 876-884.

19 Chinn S, Janson C, Svanes C, et al. The relation of adult bronchial responsiveness to serious childhood respiratory illness in the ECRHS. Respir Med 2007; 101: 983-988.

20 Chinn S, Jarvis D, Luczynska CM, et al. An increase in bronchial responsiveness is associated with continuing or restarting smoking. Am J Respir Crit Care Med 2005; 172: 956-961.

21 Chinn S, Arossa WA, Jarvis DL, et al. Variation in nebulizer aerosol output and weight output from the Mefar dosimeter: implications for multicentre studies. Eur Respir J 1997; 10: 452-456.

22 Hankinson JL, Odencrantz JR, Fedan KB. Spirometric reference values from a sample of the general U.S. population. Am J Respir Crit Care Med 1999; 159: 179-187.

23 McLeish S, Turner SW. Gene-environment interactions in asthma. Arch Dis Child 2007; 92: 1032-1035.

24 Gehring U, Bischof W, Schlenvoigt G, et al. Exposure to house dust endotoxin and allergic sensitization in adults. Allergy 2004; 59: 946-952.

25 Zambelli-Weiner A, Ehrlich E, Stockton ML, et al. Evaluation of the CD14/-260 polymorphism and house dust endotoxin exposure in the Barbados Asthma Genetics Study. J Allergy Clin Immunol 2005; 115: 1203-1209.

26 Bottcher MF, Bjorksten B, Gustafson S, et al. Endotoxin levels in Estonian and Swedish house dust and atopy in infancy. Clin Exp Allergy 2003; 33: 295-300.

27 Douwes J, Zuidhof A, Doekes G, et al. ( $1 \rightarrow 3)-\beta$-D-glucan and endotoxin in house dust and peak flow variability in children. Am J Respir Crit Care Med 2000; 162: 1348-1354.

28 Giovannangelo M, Gehring U, Nordling E, et al. Determinants of house dust endotoxin in three European countries - the AIRALLERG study. Indoor Air 2007; 17: 70-79.

29 Thorne PS, Cohn RD, Mav D, et al. Predictors of endotoxin levels in U.S. housing. Environ Health Perspect 2009; 117: 763-771.

30 Michel O, Nagy AM, Schroeven M, et al. Dose-response relationship to inhaled endotoxin in normal subjects. Am J Respir Crit Care Med 1997; 156: 1157-1164.

31 Eder W, Klimecki W, Yu L, et al. Opposite effects of CD 14/-260 on serum IgE levels in children raised in different environments. J Allergy Clin Immunol 2005; 116: 601-607.

32 Williams LK, McPhee RA, Ownby DR, et al. Gene-environment interactions with CD14 C-260T and their relationship to total serum IgE levels in adults. J Allergy Clin Immunol 2006; 118: 851-857.

33 Williams LK, Oliver J, Peterson EL, et al. Gene-environment interactions between CD14 C-260T and endotoxin exposure on Foxp3+ and 
Foxp3-CD4+ lymphocyte numbers and total serum IgE levels in early childhood. Ann Allergy Asthma Immunol 2008; 100: 128-136.

34 LeVan TD, Von Essen S, Romberger DJ, et al. Polymorphisms in the CD14 gene associated with pulmonary function in farmers. Am J Respir Crit Care Med 2005; 171: 773-779.

35 Heesen M, Bloemeke B, Heussen N, et al. Can the interleukin-6 response to endotoxin be predicted? Studies of the influence of a promoter polymorphism of the interleukin- 6 gene, gender, the density of the endotoxin receptor CD14, and inflammatory cytokines. Crit Care Med 2002; 30: 664-669.

36 Bousquet PJ, Hooper R, Kogevinas M, et al. Number of allergens to be tested to assess allergenic sensitization in epidemiologic studies: results of the European Community Respiratory Health Survey I. Clin Exp Allergy 2007; 37: 780-787. 